\title{
Hvorfor rødmet Maria Teresia?
}

\author{
Med utgangspunkt i en tekst i Tidsskriftet fra 1931 om manglende seksualkunnskap trekkes \\ her tråder til keiserinnen av Østerrike-Ungarn. Hun ble etter hvert mor til en stor barneflokk \\ - men først etter at hennes lege hadde hvisket henne noen forløsende ord.
}

\begin{abstract}
Historien er full av mysterier. Selv med de beste informanter, arkiv og arkeologiske metoder vet vi bare en brøkdel av hva som har skjedd opp gjennom tidene. Noen historiske personer er åpenhjertige og forteller mye av hva de vet, mens andre er tause og tar mysteriene med seg i sin dype grav. Et slikt mysterium er knyttet til keiserinne Maria Teresia (1717-80) av Østerrike-Ungarn. Allerede som 23-åring ble hun utnevnt til keiserinne. Hun var både politisk mektig og barnerik, og barna hennes giftet seg inn i de fleste europeiske kongehus. Således spredde genene fra den habsburgske keiserlige familie seg, og keiserinnen ble stammor til nesten alle noble familier i Europa. Derfor het det seg at keiserriket ikke fikk politisk innflytelse gjennom å føre krig - for dem tapte de nesten alle sammen - men heller ved å gifte seg inn $\mathrm{i}$ andre lands kongefamilier og få barn med dem.
\end{abstract}

I 1736, i en alder av 18 år, giftet hun seg med Frans Stefan (1708-65) av Lothringen, storhertug av Toscana. De var gift en kort tid, men så kom det ingen barn, og da begynte det å spøke for hele det keiserlige dynasti. Derfor ble en av datidens fremste leger tilkalt for å undersøke og gi råd til den vordende keiserinne. Trolig var det Gerhard van Swieten (1700-72) som i all hast ble tilkalt fra Leiden. Historien forteller at van Swieten ble bedt om finne den direkte årsaken til hennes barnløshet. Konsultasjonen foregikk i den store hoffsalen på slottet Schönbrunn. På forhånd hadde hele hoffet benket seg på hver langside av salen, for de ante at det dreide seg om en pikant sak. Keiserinnen satt på en tronstol aller øverst i salen da den berømte legen ble ført inn gjennom dørene aller nederst. Han skred verdig opp til keiserinnen, knelte ned og kysset hennes hånd og ble deretter anvist plass på en stol like foran tronstolen. Det var tyst i salen og stor spenning om hva som nå skulle skje. Hele hoffet lyttet oppmerksomt.

Maria Teresia bøyde seg ned og hvisket legen noe i øret. Så strakte han seg opp og hvisket henne noe i øret. Et øyeblikks pause, og hun hvisket ham noe tilbake. Så strakte han seg på ny frem og hvisket henne noe i øret. Da ble keiserinnen sprut rød i fjeset. Deretter fikk hun 16 barn. Alle døtrene hennes ble også barnerike, og en av dem skal visstnok ha født hele 21 barn, selv om mange av barnebarna til keiserinnen døde som små.

Maria Teresia hadde en gang tidligere forsøkt å få van Swieten til Wien som sin livlege. Da han fikk tilbudet på nytt, flyttet han i 1745 til Wien for godt for å bygge opp det medisinske fakultetet. Det gjorde han med stor kløkt og energi, og foruten å reorganisere og lede hele det østerrikske medisinalvesen ble han Maria Teresias faste livlege. I takknemlighet gjorde hun ham også til minister (1).

Hva den berømte legen hadde hvisket henne i øret har ettertiden aldri fått vite. I alle fall fikk jeg det fortalt slik under ett av mine mange besøk på Allgemeines Krankenhaus i Wien i 1970- og -80årene. Da jeg ga ut en bok om anekdoter i medisinen i 1986, tok jeg med denne historien (2). I Wien ble den beskrevet som en av gynekologiens best bevarte hemmeligheter gjennom tidene: Hva hvisket van Swieten? Om vi bare hadde visst det, så kunne kanskje mange barnløse ektepar hjelpes. Vi vet heller ikke om det virkelig var van
Swieten som ga henne dette hemmelige rådet. Som nevnt flyttet han til Wien først flere år senere, men for en god anekdote settes det ikke krav til historisk autentisitet. Ifølge overleveringene er historien tillagt ham.

Da kom det et brev fra pensjonert overlege i indremedisin på Kongsberg, Johannes Hagtvet (1904-89) - for han visste det. Ad hvilke veier dette viktige rådet var kommet til Kongsberg skrev han ikke, men han viste til en artikkel i Tidsskriftet fra 1931, der forfatteren, Henrik Arnold Thaulow Dedichen (1863-1935) gjenga hele sitatet på korrekt latin. Og Dedichen var ikke noen hvem som helst. Han var en av de førende psykiaterne i Norge på den tiden og hadde et stort forfatterskap bak seg. Han skrev både om sinnslidelser, om rettspsykiatriske problemstillinger og aktuelle samfunnsspørsmål i tillegg til artikler om kunst, litteratur og medisin i norske fagtidsskrifter og aviser. I Tidsskriftet var han en flittig bidragsyter. Han sto også bak opprettelsen av Dr. Dedichens klinikk på Trosterud i Østre Aker, eller Dr. Dedichens privatasyl, som det het opprinnelig (3).

I artikkelen Frigide fruer og klodrianer til ektemenn tok han opp aktuelle samlivsproblemer $\mathrm{i}$ en tidsepoke der mange nygifte par manglet helt elementære kunnskaper om menneskets seksualliv. Dette emnet var omhyllet av taushet og stor mystikk, og Dedichen er forbausende moderne i sine synspunkter på hva dette kan medføre. Det er verdt å minne om at på samme tid hadde den unge legen Karl Evang (1902-81) erkjent det store behovet for seksualopplysning, og i årene 1932-35 var han primus motor bak Populaert tidsskrift for seksuell opplysning, som kom i store opplag.

Dedichens artikkel er skarpsindig og til ettertanke, og blir derfor presentert som den aller første $i$ vår nye serie med kuriøse medisinske artikler.

Ole Didrik Lærum

ole.larum@gades.uib.no

Ole Didrik Lærum (f. 1940) er professor emeritus i patologi ved Gades institutt, Universitetet i Bergen.

Jeg takker Øivind Andersen, professor i klassisk filologi ved Universitetet i Oslo, for god hjelp med det latinske språket.

Litteratur

. Schönbauer L. Das medizinische Wien. Berlin: Urban \& Schwarzenberg, 1944: $105-43$.

2. Lærum OD. Fra blodigler til datamaskin: muntre legehistorier: utgitt i forbindelse med Den norske lægeforenings 100-års-jubileum. Oslo: Hjemmet-Fagpresseforlaget, 1986: 85 .

3. Larsen $\emptyset$, red. Norges leger. Bd. 1. Oslo: Den norske lægeforening, 1996: $648-50$ 


\section{Ordforklaringer}

Originalsitatet og en direkte oversettelse av van Swietens ord er slik: Ego mehercule credo, vulvam sacratissimae Majestatis ante coitum longius esse titillendam $=$ Jeg tror ved Hercules at den allerhelligste Majestetens vulva bør kiles lenge like før coitus. Eller på enklere og mer utførlig norsk: Minsanten tror jeg at den allerhelligste Majestetens kjønnslepper bør underkastes langvarig kiling før samleie finner sted.

Noen utfyllende saksopplysninger: Ved Hercules er et gammelt og ganske mildt kraftuttrykk som kan tilsvare minsanten på norsk. $\AA$ kile heter titillare på latin og kitzeln på tysk (1). Det tilsvarende latinske substantivet Titillatio (tysk: Kitzeln, fransk: chatouillement) oversettes med «kiling, kildrende fornemmelse, behagelig følelse». På fransk brukes også uttrykket les chatouillements de l'amour propre. Klitoris kalles der Kitzler på tysk.

\section{Litteratur}

1. Gessner JM. Etymologisches Wörterbuch der lateinischen Sprache. Frankfurt: C.G. Herteln, 1772

\section{Frigide fruer og klodrianer til ektemenn}

Av Henrik A. Th. Dedichen Tidsskrift for Den norske Lægeforening (Tidsskrift for praktisk Medisin) 51. årgang 1931, s. 369-372

En æret kollega har som «Landslæge» sluttet sig til over1æge Nitters uttalelse om, at størsteparten av kvinnene ikke tilfredsstilles ordentlig under samleiet. Derom vet vi nu foreløbig ikke noget sikkert. Der er ikke mange læger - ser det ut til -, som spør om slikt, og enda ferre spør riktig. Derfor får de ikke ordentlig svar. Det skal villig innrømmes, at emnet hører til de vanskeligste, en kan gi seg i kast med; men det gjelder både mann og kvinne, at spør man riktig, og får de adspurte det sikre inntrykk, at her kan de uttale sig med trygghet, visse på å bli riktig forstått, så føler de det som en befrielse en gang å kunne få tale ut - og da er det meget rart, man får høre, og det meste støtter overlægens påstand.

For et slektledd eller to siden blev ungdommen holdt i størst mulig uvitenhet om kjønnsspørsmålet. Det vil si det gjaldt da nærmest kvinnen, for mannen, han fikk nok rede på det allikevel. Jeg har oplevet tilfelle, hvor en ung pike, skremt av den første menstruasjons, efter hennes skjønn, umotiverte blødning, gikk til sin mor og der blev schnøde avvist. «Slikt snakker ikke en anstendig pike om til nogen,» sa moren. Ikke en forklaring; ikke et beroligende ord, ikke en hygienisk veiledning! Det var morens plikt på bryllupsdagen å gi datteren visse oplysninger, men ellers fikk de forlovede aldri lov til å være uten øien- eller i det minste ørenvidner. Man kan visst også gå ut fra, at de oplysninger, moren i siste øieblikk gav, har vært orakelmessig tåkede nok og lite skikket til for den unge pike å forandre alt det, hun hittil hadde ansett for urent, uanstendig, upassende og alt annet på

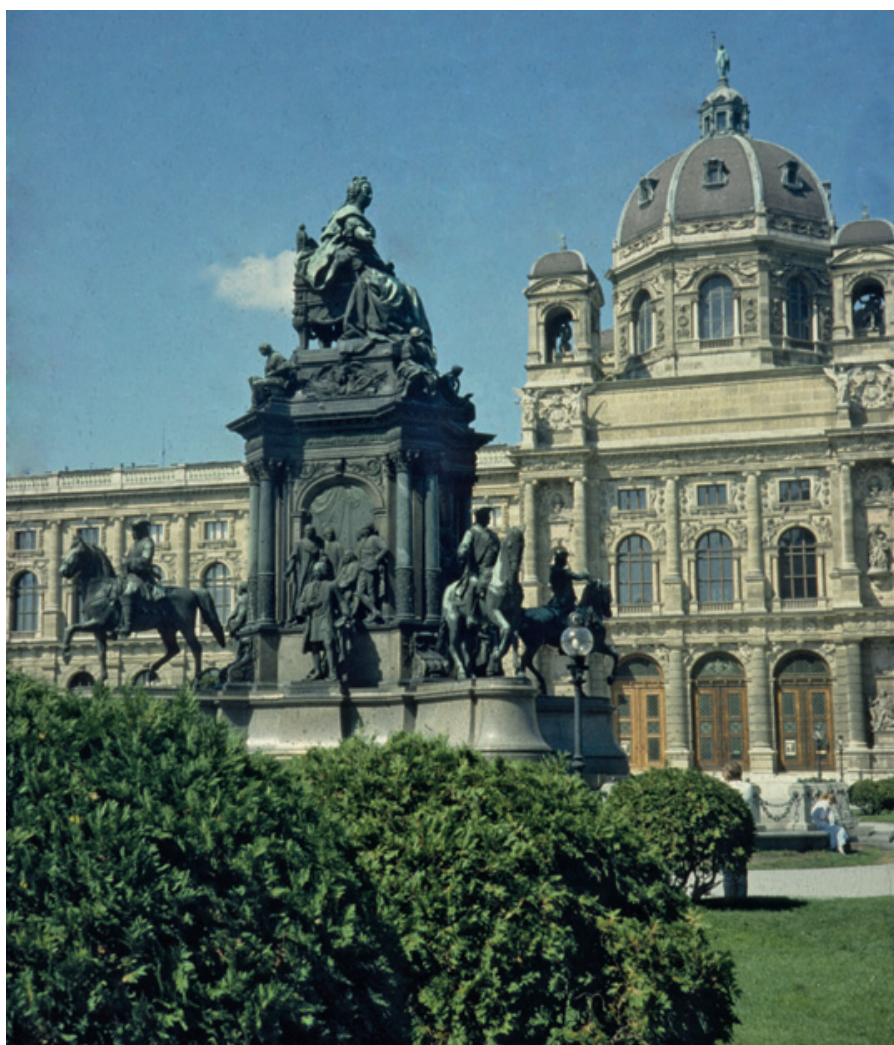

Mellom de store museene midt i Wien troner keiserinne Maria Teresia på sitt monument, og under tronstolen er det skulpturer av hennes mest betrodde ministere. Foto 0. D. Lærum

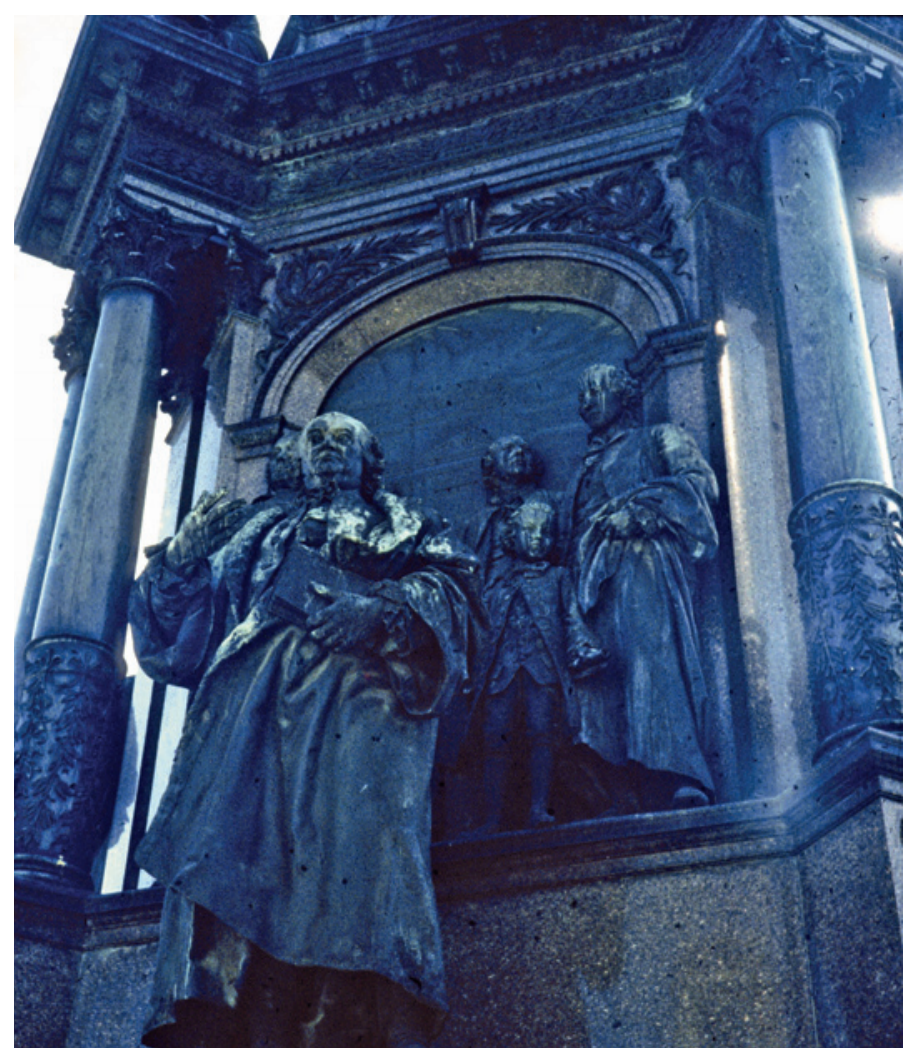

Så takknemlig var hun overfor sin livlege Gerhard van Swieten at hun ikke bare gjorde ham til preses på det medisinske fakultet, men også til minister. Derfor står denne statuen av ham ved keiserinnens føtter for å vise hvor store ringvirkninger det kan ha å gi gode medisinske råd. Foto O. D. Lærum 
$\mathrm{u}$, til det største, helligste og lykkeligste livet kunde by henne. Alt det er vel anderledes nu; men der hopper visst fremdeles mangen en ung pike i brudeseng uten å vite, hvad der egentlig venter henne der.

Undertiden får hun en mann, som er - også han - debutant på elskovsstien, og jeg tror, hun - tross alt - skal takke til. Mange mannfolk er ganske visst nogen store klodrianer, og dertil kanskje også tåpelige, så de ikke forstår, det lønner sig ikke på dette område å være egoist. Men, når «Landslæge» forteller, at en brudgom - til og med en kollega - tok gift, bryllupsnatten, fordi han fikk en ejaculatio præcox, tror jeg, det må være et eventyr. Den oplevelse må vel snarere kalles fysiologisk enn patologisk, og en time senere (eller endog før!) vilde han sikkert være annet til mann.

Hymen er ganske visst ikke noget bombesikkert vern mot en inntrengende erobrer; men den kan volde bryderi nok. Hvis den ikke sprenges helt ved første stormløp, og helst får ligge nogen dager urørt, før neste angrep kommer, kan man komme til å gjøre så smertefulle erfaringer om det ekteskapelige samliv, at en vaginisme er resultatet. Heldigst er begge parter, om han samtidig får en dyp revne i præputium, for så kanskje de begge venter med videre øvelser til sårene er helet. Endeløse er rekken av de vittigheter, som er ødslet på den mere eller mindre uheldige deflorasjon, - den som i virkeligheten ofte nok er en stillferdig tragedie, under hvilken mange menneskers hele livslykke lider skibbrudd.

Der tales i våre dager så meget om kameratekteskap. Det tør vel hende, at de fleste av oss vilde skremmes av den tanke, at vår datter skulde prøve en to-tre-fire kandidater under et samleie, før hun bestemte sig for den beste. Så forunderlig er det, at en mann kan og efter manges opfatning bør ha gjort sine erfaringer før ekteskapet, og om en kvinne gifter sig offisielt annen eller tredje gang, så er hun like god, om hun så dessforuten i det stille - NB hemmeligen - har hatt tyve elskere. Men som ugift er hun ikke da lenger førsteklasses. Hun er diskvalifisert. Følgen er, at en forsiktig ung pike gir sig ikke hen, før hun har prestens eller futens underskrift på, at nu er det uten risiko. $\mathrm{Og}$ den uanstendigste av alle fester går av stabelen! Hele slekten trommes sammen, og når brudeparret reiser, kan endog den fattigste fantasi med klokken $\mathrm{i}$ hånden forespeile en, hvad som skjer. Og dagen efter må de nygifte løpe spissrot for øine, som står på stilker.

Hvis forlovelsestiden er, hvad den bør være, vil kjærtegnene bli mere og mere nærgående og skrittvis nå derhen, at der er bare den endelige hengivelse igjen. Når den kommer i det psykologisk riktig øieblikk - som hverken prest eller fut bestemmer -, vil deflorasjonen i regelen foregå så raskt og så fullstendig, at den nesten ikke merkes, især hvis han har fått det kloke råd å salve sig, før det avgjørende inngrep skjer. Ingen mann skulde nærme sig sin elskede uten å ha sørget for, at immissio således kunde finne sted nesten umerkelig lett. Allerede på dette punkt syndes uhyggelig.

Der er noget, man kunde fristes til å kalle samleiets teknikk, men i det fag gis der mig bekjent ingen lærebok. Mange vil dog ennu med utbytte lese Emil Rodes artikkel i dette tidsskrift 1896. Hvad skal da en stakkars uerfaren yngling gjøre - og sådanne finnes virkelig. Jeg kjenner flere tilfelle, hvor han efter en kort mislykket forsøksrekke har opgitt saken helt, så der i et mangeårig ekteskap ikke har funnet et eneste virkelig sam- leie sted. Er det ikke komisk? Jeg finner det nu tvertom i høieste grad tragisk, nesten like så tragisk og undertiden vel så tragisk, som når hun undfanger gang på gang uten nogen sinne å ha erfart, hvad orgasme er. Jeg skal vel vokte mig for å tale inngående om psykoanalyse - man får inte reta djuren men skjønt vi sinnssykelæger på dette område av de innviede betraktes som rene legmenn, så har vi nu sett litt og gjort våre eraringer vi med. Og dog er der ikke tvil om, at like så sikkert som det er, at intet kan, under de riktige forutsetninger, binde menneskene tryggere sammen enn samleiet og dets resultat, barnene, like så sikkert er det at nettop det kan skape en uoverstigelig avgrunn mellem dem, i det daglige samvær. Og så skulde der til en begynnelse rimeligvis ikke mere til enn litt kyndig varsomhet, litt mennesklok forståelse av, at

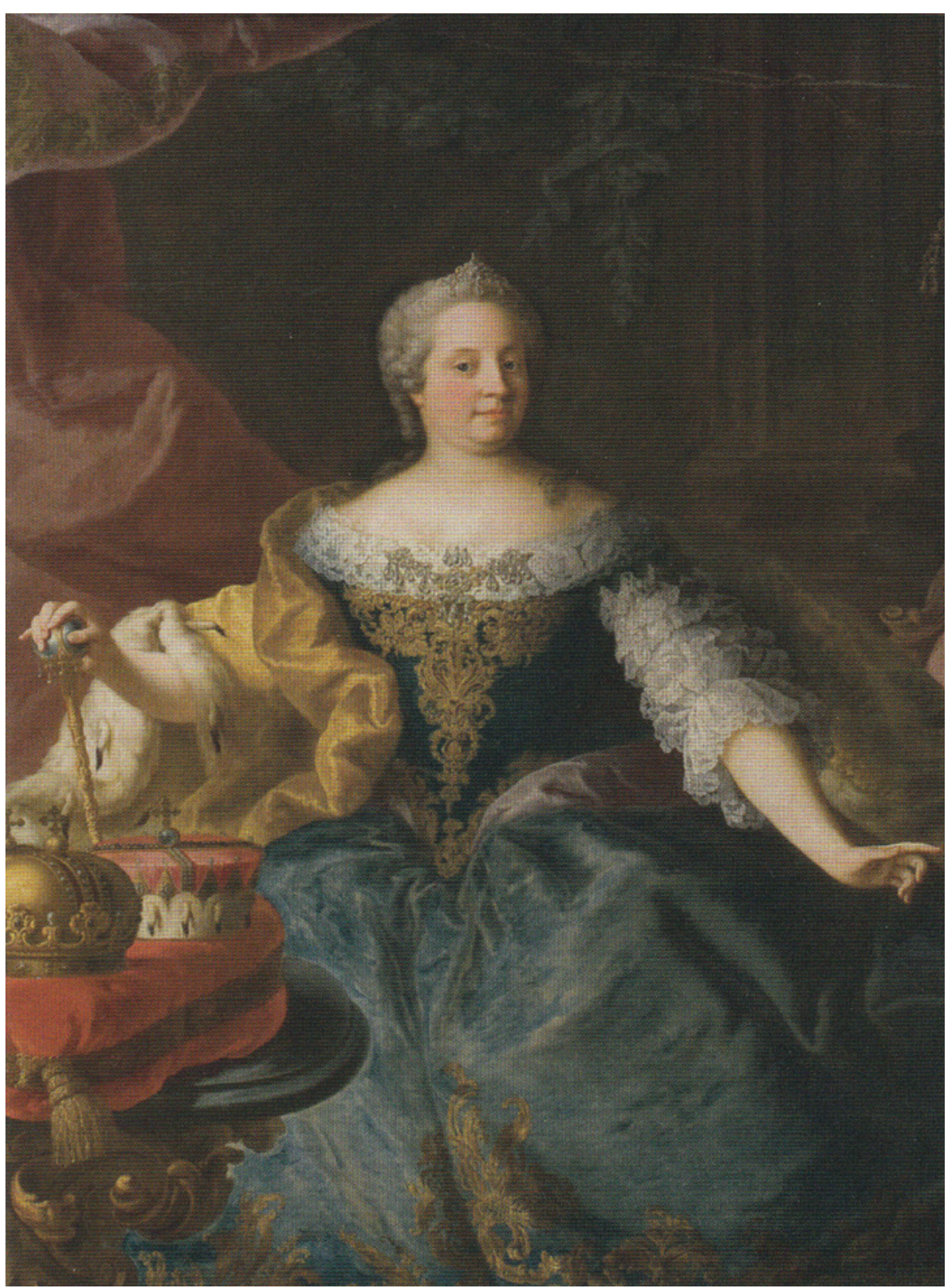

Maria Teresia i sine velmaktsdager. Etter maleri fra skolen til Martin von Meytens (1695-1770). L'Academie royale de Belge, Brüssel. Foto Olivier Damme og Philippe Molitor 


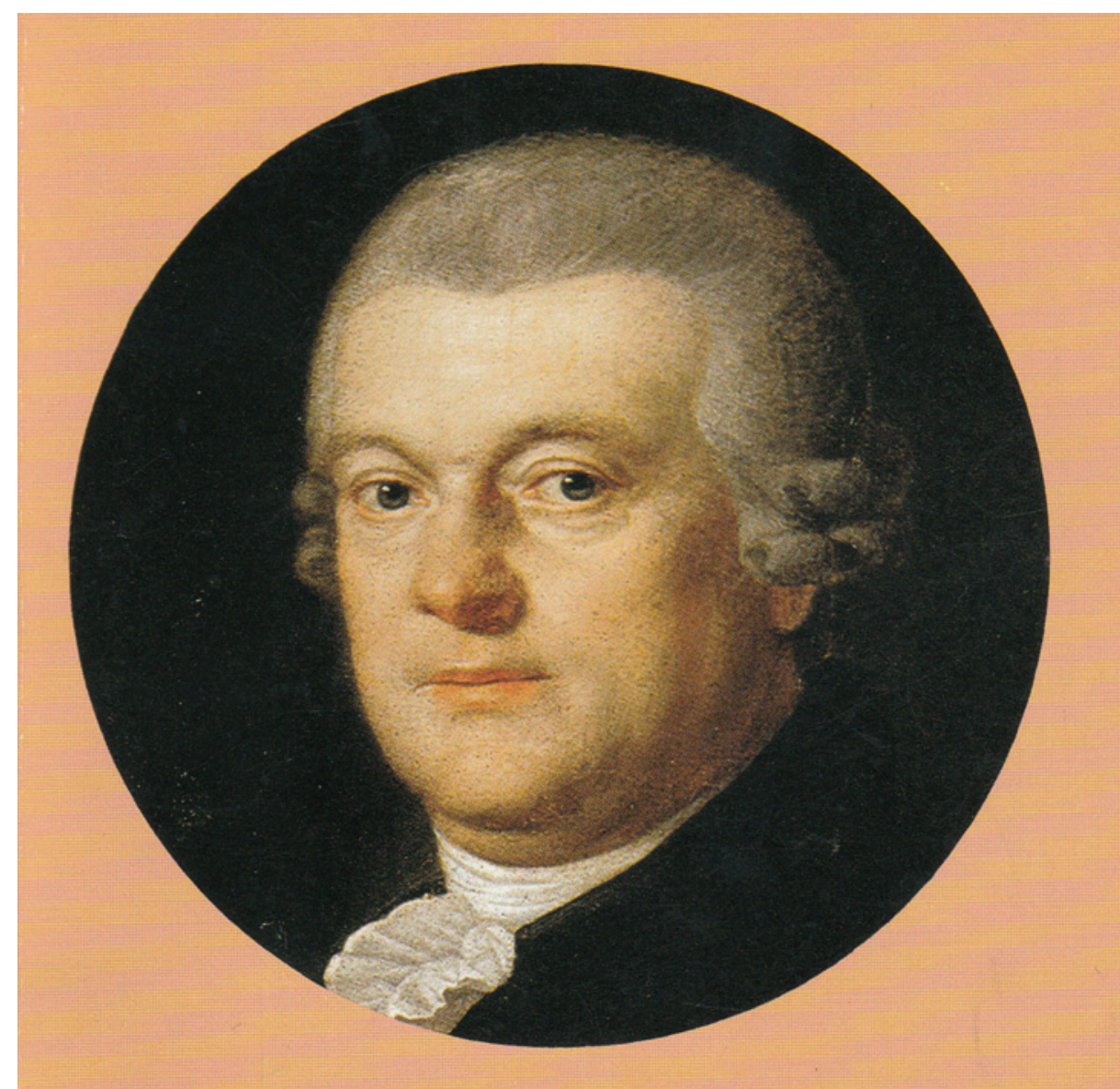

Gerard van Swieten. Utsnitt fra usignert oljemaleri på Allgemeines Krankenhaus i Wien. fFoto R. Nedorost, Wien 1981

et harmonisk samspil her krever medvirken av to. En mann kan ikke gå til et samleie, uten at han psykisk og fysisk er innstillet på det. Han skulde aldri glemme, at en kvinne har det likedan, hvis hun skal kunne leve med, og ikke bare bli ham det mekaniske instrument, hans neve i nødsfall kan yde ham sin hjelp med nesten like godt. Mellem to, som virkelig holder av hinannen, er alle uten undtagelse alle - de kjærtegn tillatt, som kan hitføre den forberetthet som er nødvendig for et ideelt samleie. Van Svietens ord om Maria Theresia - «ego mehercule credo, vulvam sacratissimae Majestatis ante coitum longius esse titillendam» - rummer $i$ all sin enkelhet en dyp sannhet, som kan gjøre tusener av mennesker lykkelige.

Jeg har her vesentlig talt om den kvinnelige frigiditet og stiltiende forutsatt, at mannen nesten alltid er potent og den, som tar initia- tivet. Man går almindeligvis ut fra, - men det er ganske upsykologisk - at det er hans plikt hele livet igjennem alltid å lokkes bare av den ene samme kvinne, som han nu engang har bundet sig til. Hvis kvinnene visste, hvor sterkt det polygame drag i mannens natur ofte er, og hvor ofte han fristes på den aller behendigste måte, så vilde de kanskje forstå, at det kunde lønne sig for dem å opta konkurransen med de frie fugler. Mangen en hustru, som pint av skinssyke er blitt redd for, at nogen skulde stjele mannen fra henne, har - kanskje veiledet av et klokt råd - opdaget, at også hun kunde forføre sin mann, og det med rikere utbytte enn om hun nådigst nu og da tilsteder ham adgang til sitt leie. Skjønt mannen som regel meget snart opdager å bli forført av sin egen kone, og det desto mere, jo finere hennes snarer legges. Det skulde kvinnene betenke og anstrenge sig for en gang iblandt å være nye for sine menn og derved erobre dem tilbake, når vanelivet truet med å la dem gli altfor langt bort.

Hvad jeg her har fremholdt, bygger på en menneskealders overordentlig tallrike betroelser. Og ingen må tro, de skriver sig fra sinnssyke alene. Tvertom. Fåtallet er fra dem. Det kreves bare, at den, hvem skoen trykker, får tillit, og meddelelsene kommer som en foss. Et forpint sinn er lettet og takknemlig, selv hvor man ingen større hjelp kan bringe, fordi den aller siste vanskelighet ligger i det forhold, som en åndfull franskmann har uttrykt således:

Ou'est-ce que c'est l'amour? L'échange de deux fantaisie et le contact de deux épidermes. 